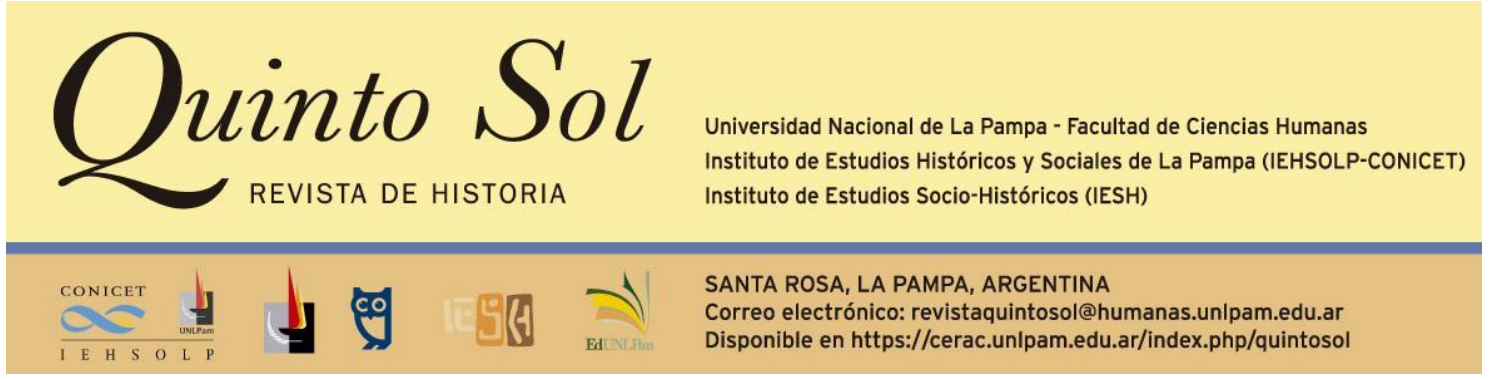

Quinto Sol, vol. 26, no 1, enero-abril 2022, ISSN 1851-2879, pp. 1-3

http://dx.doi.org/10.19137/qs.v26i1.5188

Esta obra se publica bajo licencia Creative Commons 4.0 Internacional. (Atribución-No ComercialCompartir Igual)

\title{
Maximiliano Fiquepron. Morir en las grandes pestes. Las epidemias de cólera y fiebre amarilla en la Buenos Aires del siglo XIX. Siglo XXI, 2020, 192 páginas.
}

\author{
Nicolás Fernán Rey \\ Universidad Nacional de San Martín. Instituto de Altos Estudios Sociales \\ Argentina \\ Correo electrónico: nicomics27@outlook.es
}

El presente libro, Morir en las grandes pestes. Las epidemias de cólera y fiebre amarilla en la Buenos Aires del siglo XIX, de Maximiliano Fiquepron, es un interesante estudio que refleja cómo las sociedades padecen, piensan y relatan eventos epidémicos calamitosos. El autor, historiador doctorado en Ciencias Sociales por la Universidad Nacional de General Sarmiento, se especializa en los aspectos socioculturales de Argentina durante la segunda mitad del siglo XIX. Su tesis doctoral del año 2015 fue galardonada con el premio máximo de la Asociación Argentina de Investigadores en Historia y publicada por la editorial Siglo XXI.

El objetivo central del autor a lo largo de la obra es reconstruir, desde la historia sociocultural de la enfermedad, las narraciones y representaciones sobre la salud y la muerte que percibieron los porteños. El trabajo se encuentra en diálogo, sobre todo, con los autores de la escuela sociocultural francesa y británica que han estudiado las percepciones sociales durante las grandes pestes de la edad moderna y contemporánea. Además de utilizar relatos de los contemporáneos y de fuentes periodísticas, el trabajo está sustentado en una revisión de los archivos de la ciudad de Buenos Aires, los cuales contienen diferentes actas de la municipalidad porteña durante 
los años abordados en la investigación. La obra se divide en seis capítulos y su recorte temporal se sitúa durante las epidemias de cólera y de fiebre amarilla que acontecieron en la ciudad desde 1852 hasta 1871. La hipótesis central sostiene que las pestes funcionaron como un "vector de institucionalización" de políticas estatales hacia diferentes campos que perduraron en las prácticas porteñas, incluso, hasta el presente.

A lo largo de las páginas el autor se ocupa de presentar a quienes ostentaban el campo del conocimiento medicinal y sus instituciones. Buenos Aires, inmersa en un proceso de integración con el resto de la república y de apertura al comercio y flujos migratorios mundiales, fue sacudida por enfermedades que pusieron a prueba sus órganos institucionales y a la población misma. La investigación de Fiquepron gana profundidad al tratar los temas vinculados a las representaciones sociales durante las epidemias, enriqueciendo los aportes de la historia sociocultural. Cabe remarcar que este anclaje no había sido desarrollado anteriormente con las herramientas metodológicas de la mencionada corriente historiográfica.

A su vez, el libro se adentra en las prácticas funerarias porteñas y en cómo estas se vieron alteradas por las epidemias, incluida la muerte del vicepresidente Marcos Paz en 1868, su funeral de Estado y la consecuente acefalía del gobierno nacional. Se analiza cómo eran interpretadas, desde los distintos sectores sociales, las inhumaciones y el destino de los muertos cuando se rompen los rituales tradicionales. Se evidencia la tendencia a la segregación espacial clasista de la sociedad porteña que se comenzó a gestar con el desarrollo de las epidemias. Incluso luego de la muerte, las elites procedieron a ubicar a sus difuntos en los nichos reservados a sus familias, constituyéndose así espacios jerárquicos dentro de los mismos enterratorios de la ciudad. Esto se ve reflejado en los análisis que aporta el autor sobre los registros de exhumaciones en el cementerio de la Recoleta, mucho más exclusivo y diferenciándose de lo que ocurría en la Chacarita o el Cementerio del Sud, donde se prolongaron las fosas comunes. Como asegura Fiquepron, surgieron rituales que intentaron suplantar los tradicionales, incluso, en tiempos posteriores a la muerte y el entierro del difunto.

La obra también refleja un recorrido historiográfico a través de los trabajos que abarcaron las epidemias que afrontó la ciudad de Buenos Aires. Los más importantes de estos relatos, que responden a una "modelización de la epidemia", corren desde el año 1932 hasta 1974 y tratan específicamente sobre la peste de fiebre amarilla de 1871. Se observa una tendencia en los textos a construir relatos dramáticos de los hechos, sirviendo la epidemia como una igualadora social frente a la enfermedad y la muerte ya que, entre otras cosas, habría reforzado la identidad nacional de quienes la padecieron. A su vez, todos los autores analizados pretenden reflejar la debilidad de los organismos estatales, realzando como "prohombres" de la época a médicos, políticos o periodistas. Fiquepron desmitifica la mirada otorgada por los historiadores de la Nueva Escuela Histórica argentina que omitieron, aparentemente adrede, datos sobre la participación de los organismos municipales. El relato construido desde dicha historiografía daba a entender que la actuación de las instituciones estatales se vio opacada por la pérdida de legitimidad política y por su débil poder de acción. Por ende, grupos autoconvocados de civiles habrían realizado los trabajos que les corresponderían a los gobiernos. De esta manera, se buscó recordar el hecho de una forma dramática y caótica, reescribiendo una historia institucional y política con una narración 
nacionalista. Uno de los puntos centrales de la obra de Fiquepron es que, a través de los archivos de la municipalidad, se evidencia una activa participación de esta a través de diferentes organismos públicos como eran los de higiene, beneficencia y las comisiones parroquiales.

A modo de conclusión, comprendemos que la obra reseñada es un nuevo acercamiento ameno a un tema que ha sido trabajado profusamente en libros y artículos por la historiografía argentina. El mayor aporte del autor reside en anclarlo metodológicamente en la historia sociocultural, rebatiendo ciertos temas que, sobre todo en el último tiempo y debido al contexto de pandemia que atraviesa el mundo, se seguían reproduciendo como verdaderos. Un ejemplo de esta cuestión es la supuesta incapacidad de las autoridades municipales durante los hechos. Por todo esto, la obra reseñada constituye una excelente oportunidad para reflexionar acerca de estas problemáticas, lamentablemente, tan vigentes. 